Mário Guimarães Ferri, doutor em ciências

(botânica), ex-professor visitante do California Institute of Technology, conferencista da Fundação Rockefeller. Atualmente é professor da USP.

\title{
Os cerrados, um grupo de formas de vegetação semelhantes às savanas
}

\section{Conceituação}

Em sentido genérico, o cerrado é um grupo de formas de vegetação que se apresenta segundo um gradiente de biomassa. A forma de menor biomassa é o campo-sujo-de-cerrado seguindo-se, em ordem crescente, o campo cerrado, o cerrado e o cerradão.

Os três primeiros tipos se enquadram entre as formações campestres e o último é um tipo florestal de vegetação, do ponto de vista fisionômico. Quando se considera a composição florística, todavia, o cerradão cai dentro do grande domínio dos cerrados, pois as espécies que o compõem estão também presentes nas outras formas de cerrado (Relatório à Empresa Brasileira de Pesquisa Agropecuária - Embrapa, 1975, p. 3. Grupo de trabalho instituído pela Resolução n. R. D. 040/74 de 19 de novembro de 1974).

\section{Localização}

Os diferentes tipos de cerrado distribuem-se, no Brasil, em duas áreas principais: a chamada área nuclear, essencialmente de cerrados, no Planalto Central, interessa principalmente aos estados de Mato Grosso, Mato Grosso do Sul, Goiás, Distrito Federal e Minas Gerais; a área periférica, distribui-se pelo norte (Região Amazônica, ocorrendo mesmo ao norte do Equador), pelo nordeste em contato com caatingas, pelo sudeste (Estado de São Paulo) e pelo sul (Estado do Paraná). Aqui seus últimos vestígios

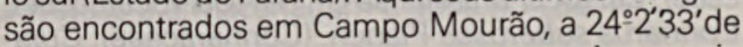
latitude Sul, em contato com a Araucaria angustifolia.

A área nuclear dos cerrados tem uma superfície de cerca de 1,5 milhão de quilômetros quadrados e a periférica cerca de meio milhão. Assim, a superfície do Brasil ocupada por essa vegetação é de $22 \%$ aproximadamente (conforme também Sanches, Lopez e Buol, 1974, in: Relatório à Embrapa, 1975).

Tabela de distribuição aproximada das áreas dos cerrados do Brasil.

\begin{tabular}{l|c|c|c}
\hline $\begin{array}{l}\text { Estado ou } \\
\text { Território }\end{array}$ & $\begin{array}{r}\text { Area de cerrado } \\
\text { (milhões de ha) }\end{array}$ & $\begin{array}{r}\text { Distribuição no } \\
\text { Estado }\end{array}$ & $\begin{array}{r}\text { Percentual do } \\
\text { cerrado no } \\
\text { país }\end{array}$ \\
\hline Goiás & 55,5 & 88 & 30 \\
Mato Grosso & 47,9 & 39 & 26 \\
Minas Gerais & 30,8 & 53 & 17 \\
Piauí & 11,5 & 46 & 6 \\
Bahia & 10,5 & 19 & 6 \\
Maranhão & 9,8 & 30 & 5 \\
Roraima & 4,4 & 19 & 2 \\
São Paulo & 4,1 & 17 & 2 \\
Pará & 3,9 & 3 & 2 \\
Amazonas & 2,0 & 1 & 1 \\
Amapá & 1,9 & 14 & 1 \\
Distrito Federal & 0,6 & 100 & 1 \\
Outros & - & - & - \\
\hline Total & 182,9 & & 100 \\
\hline
\end{tabular}




\section{Fisionomia do cerrado}

O cerrado é, em geral, uma vegetação de árvores e arbustos formando uma camada descontínua, e de gramíneas e outras herbáceas formando a camada contínua.

As plantas herbáceas só vegetam na época chuvosa, enquanto as plantas arbóreas e arbustivas lenhosas são permanentes. São, em geral, de baixo porte, tortuosas, de ramos retorcidos, cascas espessas, muitas vezes mostrando sinais de queimadas, de folhas grossas, brilhantes ou revestidas de densa camada de pêlos às vezes na face superior, outras em ambas as faces. Todos esses são caracteres que fażem pensar em adaptação à falta d'água (Ferri, 1955).

\section{Composição florística do cerrado}

O cerrado tem uma flora muito rica em espécies. Vamos citar apenas alguns exemplos dentre as espécies mais características: Anacardium pumilum St. Hil. (família Anacardiaceae), Andira humilis Mart. (Leguminosae), Annona coriacea Mart., Annona dioica St. Hil. (Annonaceae), Aspidosperma tomentosum Mart. (Apocynaceae), Byrsonima coccolobifolia Kunth., Byrsonima verbascifolia Rich. (Malpighiaceae), Caryocar brasiliense St. Hil. (Caryocaraceae), Connarus suberosus Planch. (Connaraceae), Curatella americana L. (Dilleniaceae), Dalbergia violecea (vog.) Malme (Leguminosae), Didymopanax vinosum E. March. (Araliaceae), Dimorphandra mollis Benth. (Legominosae), Erythroxylum suberosum St. Hil., Erythroxylum tortuosum Mart. (Erythroxylaceae), Hancornia speciosa Gomez (Apocynaceae), Kielmeyera coriacea Mart. (Guttiferae), Ouratea spectabilis (Mart.) Engl. (Ochnaceae), Palicourea rigida H.B.K. (Rubiaceae), Qualea grandiflora Mart., Salvertia convallariodora St. Hil. (Vochysiaceae), Tabebuia ochracea (Cham) Standley (Bignoniaceae), Tocoyena brasiliensis Mart., Tocoyena formosa Schum. (Rubiaceae), Zeyhera montana Mart. (Bignoniaceae).

As espécies antes arroladas são todas árvores e arbustos lenhosos, permanentes. Vamos indicar agora algumas efêmeras, que só vegetam na época chuvosa, no verão: Aspilia reflexa Baker (Compositae), Centrosema bracteosum Benth. (Leguminosae), Cochlospermum regium (Mart.) Pilger (Cochlisoernaceae), Craniolaria integrifolia Cham. (Martiniaceae), Manihot tripartita Müll. Arg. (Euphorbiaceae), Serjania erecta Radlk. (Sapindaceae), Vernomia grandiflora Less. (Compositae).

Mencionemos agora algumas palmeiras do cerrado, que fazem parte da vegetação permanente: Attalea exigua Drude, Butia leiospatha (Barb. Rodr.) Becc., Diplothemium campestre Mart.
As gramíneas que citaremos a seguir, pertencem à vegetação efêmera de verão: Echinolaena inflexa (Poir.) Chase, Tristachya chrysothrix Ness ab Esenbeck, Tristachya leiostachya Ness ab Esenbeck.

Volto a lembrar que estes são apenas alguns exemplos de uma flora muito rica (Ferri, 1955).

\section{Características da vegetação do cerrado}

Quando falamos sobre a fisionomia do cerrado, já indicamos as principais características morfológicas de sua vegetação arbustiva e arbórea, permanente, e que por isso mesmo domina a paisagem e dissemos, também, que a aparência faz crer numa vegetação adaptada a condições de seca. De outro lado, muitas espécies apresentam certas características que não permitem aceitar essa suposição. FoIhas de superfícies muito grandes, indivisas, ocorrem em Salvetia convallariodora, em Kieelmeyera coriacea, em Tocoyena brasiliensis e em Tocoyena formosa, por exemplo. Em Stryphnodendron barbadetimam, em Dimorphandra mollis e em inúmeras ou tras leguminosas, a enorme folha é dividida e subdividida em folíolos mais ou menos numerosos.

Naturalmente, superfícies foliares grandes não adaptam plantas e ambientes secos, pois é principalmente pelas superfícies foliares que as plantas perdem água (transpiração). Além disso, muitas espécies de cerrado produzem, em plena seca, antes das primeiras chuvas, abundante floração (por exemplo, Tabebuia ochracea) ou brotação vegetativa (a mesma espécie, terminado o curto período de floração). Ora, para formar e desenvolver flores e brotos vegetativos, muita água é necessária (Ferri, 1955, 1977).

\section{Estudos pioneiros de ecofisiologia em campos cerrados de Emas}

Observações como as mencionadas levaram Rawitscher, Ferrie Rachid a duvidarem de que a vegetação dos cerrados fosse condicionada pelo fator água. Depois de alguns anos de observações e estudos sistemáticos, num cerrado de Emas, próximo de Pirassununga, Estado de São Paulo, portanto em área periférica de cerrado, esses autores chegaram às seguintes observações e conclusões principais (1943):

- as precipitações anuais são da ordem de 1300 mm;

- há um período de seca de cerca de cinco meses;

- as reservas de água no solo que atinge 20 ou mais metros de profundidade, correspondem a precipitações de três anos; 
- 1 metro abaixo da superfície os teores de umidade no solo são elevados, mesmo na estação seca (em junho - julho 7,4\% do peso do solo secol; a partir dessa profundidade a umidade no solo aumenta muito, chegando a $40 \%$ a 17 metros, em camadas próximas do lençol freático $(19 \mathrm{~m})$;

- numa coluna de solo, da superfície até essa profundidade, a quantidade de água armazenada seria equivalente a três anos de precipitações, se nenhuma água se perdesse por evaporação, transpiração ou escoamento; como tudo isso ocorre, é claro que a água armazenada é apenas a que restou e representa o excedente de adução sobre o consumo;

- a maioria das plantas permanentes dos cerrados têm raízes profundas; as de Andira humilis podem chegar a atingir o lençol freático; Anacardium pumilum também forma sistemas radiculares muito profundos; a maioria das árvores e arbustos forma raízes de 5 a 10 metros de profundidade;

- os estômatos da grande maioria das plantas permanecem abertos o dia todo;

- em sua quase totalidade essas plantas transpiram sem qualquer restrição;

- apesar disso os déficits de saturação das folhas são baixos; os maiores encontrados eram da ordem de $6 \%$ em Palicoure a rigida;

- a conclusão a que chegaram os autores à vista desses dados, foi a de que a vegetação nativa, permanente do cerrado estudado, não é limitada pela falta d'água; o aspecto dessa vegetação deveria estar ligado a outro fator qualquer.

Mais tarde, Ferri (1944) estudou pormenorizadamente, no mesmo cerrado, a economia hídrica e a anatomia de um grande número de espécies da vegetação permanente e concluiu que as espécies estudadas não se comportavam como xerófitas e que as mesmas possuem sistemas radiculares profundos, que exploram camadas sempre úmidas de solo, o ano todo.

Em seu trabalho de 1947, Rachid estudou a transpiração e os sistemas subterrâneos de diversas espécies do cerrado de Emas, dividindo-as em três grupos. Com raízes até $1 \mathrm{~m}$ de profundidade; com raizes de 1 a $2 \mathrm{~m}$, com raízes de mais de 2 metros; a autora verificou que as espécies de raizes superficiais apresentam restrição de transpiração nos períodos mais secos do dia e que o xeromorfismo neste grupo de plantas é muito menor que no das espécies permanentes; Craniolaria integrifolia, por exemplo, tem uma estrutura que absolutamente não é de espécies de ambientes secos.

Assim, as plantas que estudou, podem restringir o consumo d'água, durante certos dias da épo- ca seca; na estação chuvosa, mesmo para estas plantas não falta água; as espécies de raízes mais profundas, porém, não sofrem falta d'água mesmo na estação seca.

De todo o exposto anteriormente, conclui-se que a vegetação nativa do cerrado estudado não é limitada pela falta de água; seu xeromorfismoé apenas aparente e deverá ser explicado por outro fator qualquer.

\section{Estudos em outros cerrados}

Ferrie Coutinho (1958) executaram estudos similares aos realizados em Emas, em cerrados da área nuclear: Campo Grande (Mato Grosso do Sul) e Goiania (Goiás); os mesmos autores também estudaram um cerrado da área periférica, bem ao sul, em Campo Mourão (Paraná, 1960) e Ferrie Lambertiestudaram outro cerrado periférico, no Nordeste, em Goiana (Pernambuco, quase divisa com Paraíba, 1960).

Os resultados a que chegaram são essencialmente os mesmos em todos os casos, exceto no último onde pequenas restrições no consumo d'água foram observadas. Mas esse cerrado tem uma camada de canga limonítica que às vezes chega a aflorar à superfície do solo. Isso, sem dúvida, cria condições adversas à armazenagem d'água no solo.

\section{Pseudoxeromorfismo}

Em 1958, Arens, baseado na literatura sobre diversas formações vegetais de todo o mundo, formulou uma hipótese geral de que o pseudoxeromorfismo que, por vezes, se manifesta como escleromorfismo, pode ser devido a qualquer fator que limite o crescimento.

Assim, sabedor de nossos resultados no cerrado e conhecendo, pela literatura, que deficiências nutricionais em condições satisfatórias de suprimento de água, $\mathrm{CO}_{2}$ e luz, podem levar a um acúmulo de carboidratos, procurou explicar o escleromorfismo foliar do cerrado como um caso de pseudoxeromorfismo. $\mathrm{O}$ aparente xeromorfismo seria, na verdade, um escleromorfismo oligotrófico.

\section{A toxidez do alumínio e o escleromorfismo oligotrófico do cerrado-}

Em 1969, Goodland, em sua tese de doutoramento, obteve dados em 110 lugares do Triângulo Mineiro, abrangendo, em todos, vários campos sujos de cerrado, campos cerrados, cerrados e cerradões. 
Coletou em todos os postos, dados sobre biomassa, densidade da vegetação, freqüência das espécies, altura, diâmetro e outras características das árvores. Coletou também amostras de solo, determinando o $\mathrm{pH}$ e os teores de $\mathrm{C}, \mathrm{N}, \mathrm{Ca}+\mathrm{Mg}, \mathrm{K}, \mathrm{Al}, \mathrm{PO}_{4}$.

$O$ autor verificou que todos os fatores estudados aumentavam do campo sujo de cerrado até o cerradão, exceto de Al, que no cerrado, menos ácido, era menos abundante que nos solos muito mais ácidos dos campos sujos.

Reportando-se aos autores que o antecederam, afirmou que a teoria de escleromorfismo oligotrófico estava fortemente apoiada pelos resultados que obteve, com um enfoque totalmente diverso dos problemas, afirmando, ainda que parte deste escleromorfismo é causada pela toxidez do alumínio, sendo que o ferro e o manganês podem completar a ação do alumínio.

Sua tese, defendida na McGill University, interessava principalmente ao Brasil, porém, só existia em língua inglesa. Em 1979, entretanto, achamos conveniente publicar o livro Ecologia do cerrado, escrito por R. Goodland e M.G. Ferri. A parte principal do livro é constituída pelos dados do primeiro autor, cabendo ao segundo apenas uma revisão da literatura do decênio, após Goodland haver defendido sua tese, e farta documentação fotográfica.

\section{Aproveitamento do cerrado}

Tendo sido demonstrado que, ao menos para a vegetação nativa do cerrado, a água não era, em geral, o fator limitante do crescimento, desde logo os agrônomos começaram a desenvolver experimentos, primeiro em laboratório, depois no campo, a fim de encontrarem a melhor tecnologia para as diferentes culturas, no cerrado. Hoje, no Brasil, acredita-se que o cerrado será o grande celeiro, não só para produção de alimentos, mas de celulose, madeira para móveis, para consumo interno e para exportação.

Muitas culturas dispensam irrigação: Eucalyptus, Pinus, café, frutíferas como manga, abacate, laranja, entre outras; cana-de-açúcar e mandioca, miIho, soja, arroz, sorgo também dão boas safras, sem irrigação. Várias dessas culturas, todavia, quando irrigadas dão maior rendimento, havendo mesmo a possibilidade de, em alguns casos, colherem-se até três safras num ano.

Há algumas culturas que só podem ser feitas, no cerrado, com irrigação: o trigo, por exemplo, mas as colheitas de trigo no cerrado estão superando, em muito, as colheitas nos locais tradicionais de seu cultivo, por exemplo o Rio Grande do Sul.
Acreditamos que, em futuro próximo, até a cafeicultura se deslocará do sul, sujeito a geadas, para regiões de cerrado, livres desse flagelo que periodicamente corrói nossa economia que ainda tem, no café, um de seus principais, senão seu principal, esteio, até o presente.

Nos cerrados é possível a formação de imensas e excelentes pastagens que, com bom manejo, permitirão um ótimo desenvolvimento da pecuária leiteira e de corte. Nessas pastagens, podem-se consorciar gramíneas e leguminosas, com produção de ótimo alimento para o gado. Essas pastagens são divididas em piquetes. O gado ocupa o primeiro, em grande número durante poucos dias; depois passa para o segundo e para o terceiro; talvez passe para o quarto ou já volte para o primeiro, se tiver se restaurado.

\section{Conclusão}

O cerrado vai permitir a expansão de nossa silvicultura, de nossa agricultura e de nossa pecuária de leite e de carne. $E$, o que é muito importante, vai proteger bastante a Amazônia, frágil, desconhecida e distante. O cerrado está muito mais próximo dos grandes centros consumidores que são os maiores núcleos populacionais do país: o nordeste, o sudeste e o sul do Brasil.

\section{Bibliografia}

ARENS, K. Consideraç̃es sobre oxeromorfismo foliar. Boletim da Faculdade de Filosofia, Ciências e Letras da USP; Botânica, 224 (15): 23-54, 1958.

O cerrado como vegetação oligotrófica. Boletim da Faculdade de Filosofia, Ciênciase Letras da USP; Botânica, 224 (15): $57-78,1958$

COUTINHO, L.M. \& FERRI, M. G. Transpiração e comportamento estomático de plantas permanentes do cerrado em Campo do Mourão (Estado do Paraná). Boletim da Faculdade de Filosofia, Ciências e Letras da USP; Botânica, 247 (17): $117-130,1960$.

EITEN, G. The cerrado vegetation of Brazil. Bot. Rev., 38 (2): 341 , 1972.

EMBRAPA. Relatório elaborado por grupo de trabalho instalado pe la Resolução n. R.D.040/74, de 19/11/1974, para preparar anteprojeto de implantação do Centro de Pesquisa para Desenvolvimento de Recursos dos Cerrados. Brasília, 1975

FERRI, M. G. Transpiração de plantas permanentes dos cerrados. Boletim da Faculdade de Filosofia, Ciências e Letras da USP: Botânica, 4 (4): 155-224, 1944.

. Contribuição ao conhecimento da ecologia do cerradoe da caatinga; estudo comparativo do balanço d'água de sua vegetação. Boletim da Faculdade de Filosofia, Ciências e Letras da USP; Botânica, 12:1-170. 
Ecologia dos cerrados. In: SIMPOSIO SOBREO CERRADO: BASES PARA UTILIZACÃO AGROPECUARIA. Coord. Mário Guimarães Ferri; SãoPaulo, Ed. Itatiaia/EDUSP, 1977. $405 P$.

\& COUTINHO, L. M. Contribuição ao conhecimento da ecologia do cerrado; estudo comparativo da economia d'água de sua vegetação em Emas (Estado de SãoPaulo), Campo Grande (Estado de Mato Grosso) e Goiânia (Estado de Goiás). Boletim da Faculdade de Filosofia, Ciências e Letras da USP; Botânica, 224 (15): 103 - 150, 1958.

\& LAMPERTI, A. Informações sobre a economia d'água de plantas de um trabalho no Município de Goiana (Pernambucol. Boletim da Faculdade de Filosofia, Ciênciase Letras da USP; Botânica, 247 (17): 131-41, 1960.
GOODLAND, R. An ecological study of the cerrado vegetation of South Central Brazil; Montreal, McGill University, 1979. $224 p$.

\& FERRI, M.G. Ecologia do cerrado. São Paulo, Ed. Itatiaia/EDUSP. 194p.

RACHID, M. Transpiração e sistemas subterrâneos da vegetação de verão dos campos cerrados de Emas. Boletim da Faculdade de Filosofia, Ciências e Letras da USP; Botânica, 80 (5) : 5-140, 1947.

RAWITSCHER, F. et alii. Profundidade dos solos e vegetação em campos cerrados do Brasil Meridional. Anais da Academia Brasileira de Ciências, 15 (4) : 267-98, 1943. 


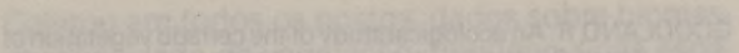

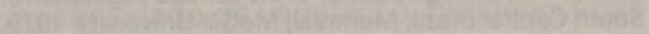

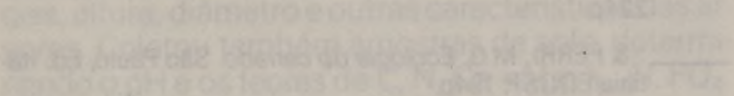

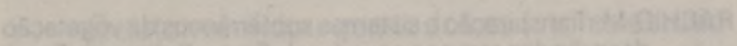

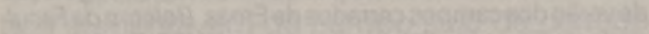

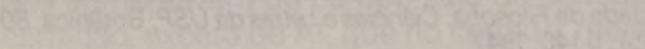

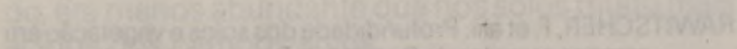

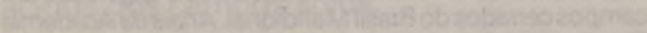

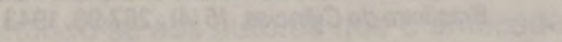

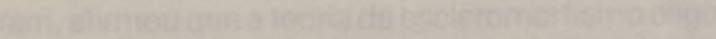

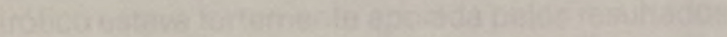

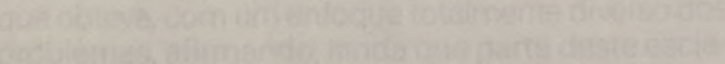

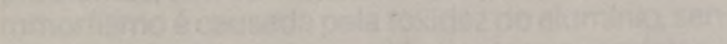

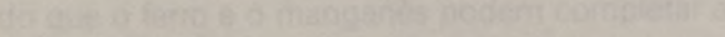

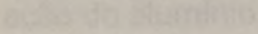

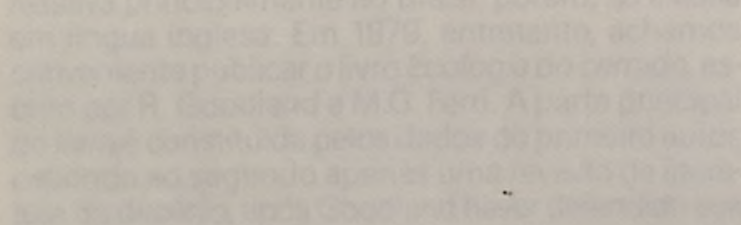

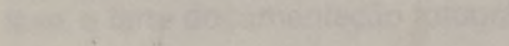

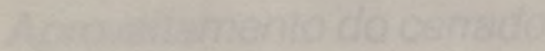

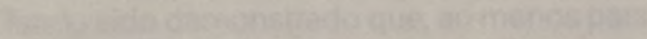

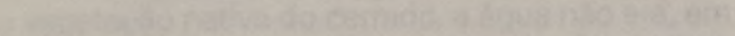

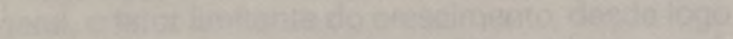

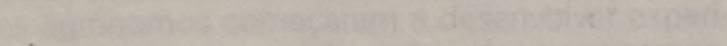

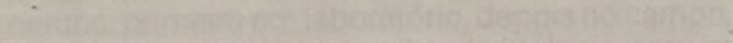

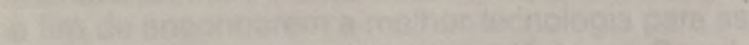

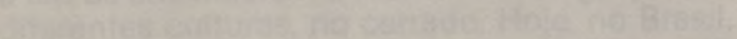

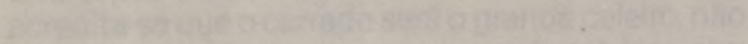

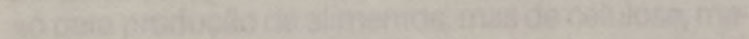

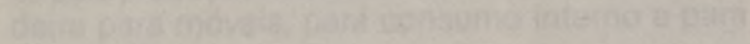

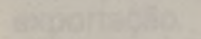

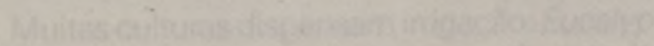

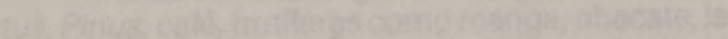

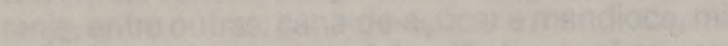

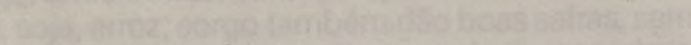

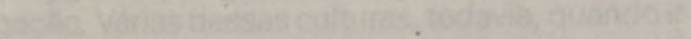

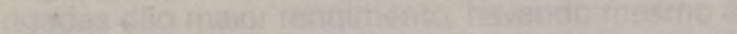

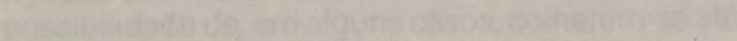

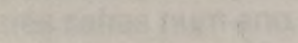

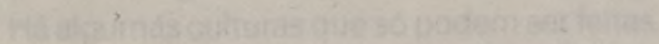

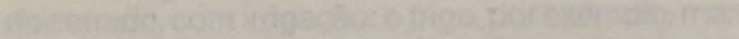

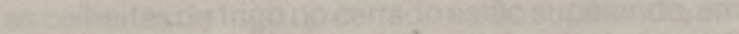

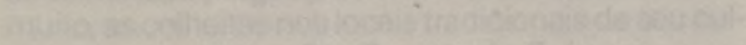

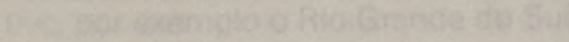

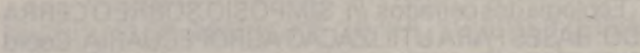

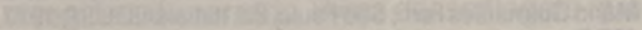
-

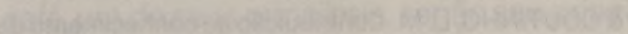

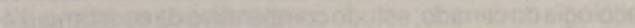

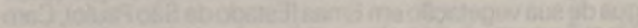

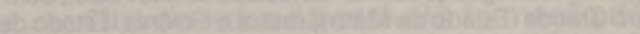

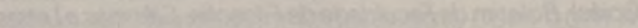

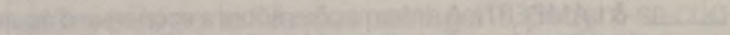

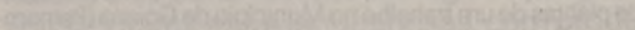

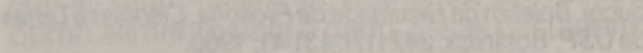

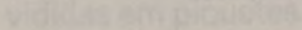

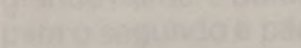

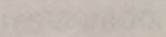

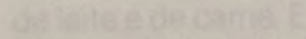

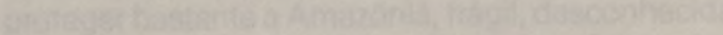

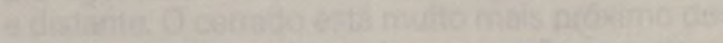

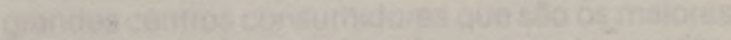

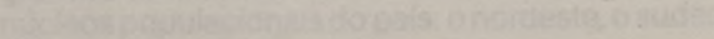

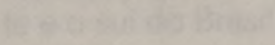

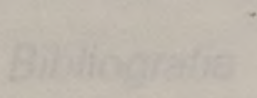

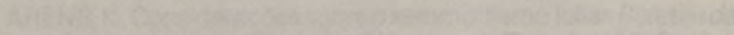

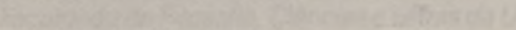

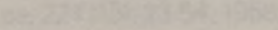

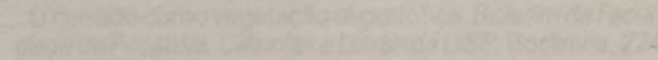

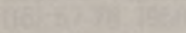

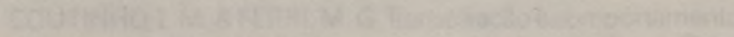

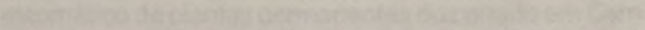

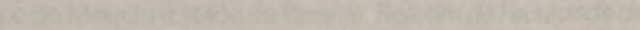

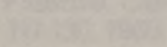

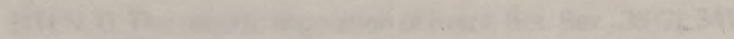

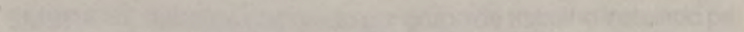

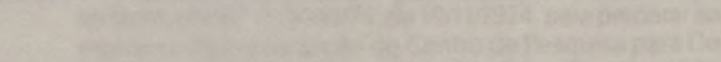

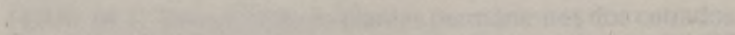

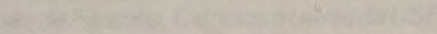

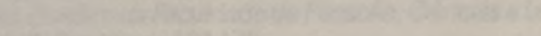

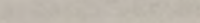

